\title{
Comment on Hou's Immigrant entry earnings over the past quarter-century: The roles of changing characteristics and returns to skills
}

\author{
Don J. DeVoretz
}

The paper by Dr. Feng Hou, 'Immigrant entry earnings over the past quarter-century: The roles of changing characteristics and returns to skills,' suffers from inadequacies in Census data. First, no entry gate definition is available in the census, and the use of source country data by the author as a proxy for immigrant characteristics is misleading for several reasons. In many cases, the source country does not reveal the country of birth but the country of last permanent residence. One cannot simultaneously control for entry gate (points assessed versus not assessed) and country of origin with census data, which is essential for this analysis since the author is concerned about skill levels and, presumably, entry gate effects. The use of India and China as new immigrant source countries (i.e., new areas of arrival) is a perfect example of where this confusion arises. Almost all recent Indian immigrant arrivals were in the family class, and almost no recent immigrants from China were in the family class. Now, what does the recent shift to these two immigrant source countries imply for a theory explaining a rise or fall in the immigrant-Canadian-born wage gap? I would suggest nothing; it is the entry class and not the source country which would affect the wage gap. One should control for entry gate and compare economic or points assessed immigrant wages by occupation to a Canadianborn matching cohort to see what happens to the wage gap of this identical cohort. This cannot be done with census data.

The next fundamental problem is the dependent variable or the measure of an earnings gap used in this study. When discrimination (positive or negative) is a big issue, as it is in this case, one should not use monthly (or yearly) earnings to measure or detect possible discrimination. Rather, it would be advisable to use the hourly wage gap. For example, during the IT boom and bust, immigrants wages did not change relative to native-born, but earnings (wages $\times$ hours) did, since immigrants were less successful in finding any job, in or out of the IT sector.

The dependent variable, educational quality, is also ill-defined in census data, since one does not know where immigrants received their education (Canada, source country, or rest of the world), and any discussion of educational quality is therefore suspect. In fact, a careful analysis of education by immigrant source country often reveals evidence of a 'sheepskin' effect which favours some foreign degrees (e.g., for immigrants from USA, the former Soviet Union, Israel, Eastern Europe, and the UK) relative to Canadian or other immigrant source countries' educational attainment. This lack of disaggregation of education by source country makes any generalization about educational quality across source countries dubious at best.

Now to the heart of the issue: The use of entry cohorts as a control group is incorrect as a way to estimate changes in the immigrant-non-immigrant 'wage gap.' At best, one can detect that the initial earnings penalty of an immigrant relative to a Canadian-born has grown, but it is not possible

\footnotetext{
* Professor of Economics, Simon Fraser University, Burnaby BC, Canada. Email: devoretz@sfu.ca
} 
to know anything of catch-up trends over time. This absence of a dynamic framework omits the phenomenon that failed immigrants — those with no jobs or low income-leave Canada in the first five years after immigration. Hence, the gap will close as low immigrant earners leave over time. Next, by concentrating on recent arrivals, one skews the aging and experience effect by definition. In addition, there is a large citizenship effect which removes all earnings differentials for all source countries relative to Canadian-born (DeVoretz 2008) after 10-plus years in Canada for naturalized Canadians. The analysis in this study misses this important integration phenomenon (in the 6-10 year) in Canada by concentrating on recent immigrant arrivals, who by definition are not citizens.

So what are we left with? We have an analysis of initial wage gap which has always been large (see Chiswick in 1978), and the real issue is how long it takes to close the gap. The use of census data in this analysis is flawed and misleading, especially when entry gates and educational quality by source country cannot be controlled for.

Finally, my major point is not to critique the use of flawed census data itself, but to point to the fact that there is a superior data set to the census-namely, the Longitudinal Immigrant Database (IMDB), which is longitudinal and follows individual immigrants from entry date, and contains more control variables than in the census. Knowledgeable readers will immediately ask why Dr. Hou did not use the IMDB data set, given the known flaws with the census data.

\section{References}

Chiswick, B. 1978. The Americanization of the earnings of foreign-born men. Journal of Political Economy 86(5):897-922.

DeVoretz, D. 2008. The economics of citizenship: A common intellectual ground for social scientists. Journal of Ethnic and Migration Studies 34(4):679-693. 